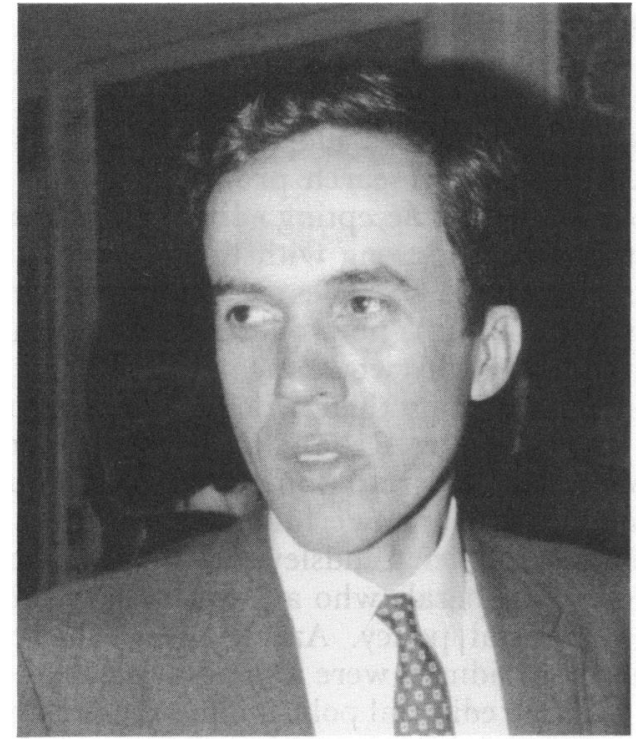

Donald S. Blough, 1968. control is not exactly the same as understanding how things work, which was my passion. The beauty of a set of numbers, or a cumulative record, may depend on such passions of the beholder, which perhaps accounts in part for the somewhat varied reactions to the JEAB viewpoint over the years.

A uniqueness that all can applaud, I think, is JEAB's 30-year status as a paragon of journal management. Most notable has been the Journal's steadfast concern for authors. Over the many years during which Pat Blough or I have served on the editorial board, we have rarely seen a review or an editorial letter that did not instruct and encourage. Charlie Ferster's sensitivity to the plight of unrequited authors lives on.

Department of Psychology
Brown University
Providence, Rhode Island 02912

\title{
Ogden R. Lindsley
}

\section{COLLEGTING THE FIRST DOLLARS FOR JEAB}

At our organizational meeting in April 1957, in Charlie Ferster's room at the Statler Hotel in New York City, I volunteered to take the notes and to be the first Secretary-Treasurer and Business Manager of JEAB. I had facilities in the Behavior Research Laboratory at Metropolitan State Hospital and a budget that could defray minor expenses. I was Business Manager until December 1959 when we hired Kay Dinsmoor to do that job, but I continued as Secretary-Treasurer until 1965.

As I recall, Peter Dews, Bill Morse, and Dick Herrnstein sat around a table in my laboratory in a basement of Metropolitan State Hospital and prepared the very first issue for mailing. We had received the journals from the printer and since we had the addresses, the money, the space, and the time, the Boston group did the mailing to our approximately 300 subscribers. We pasted thermofaxed address labels on by hand, and applied regular postage stamps. We also collated and mailed out reprints to the authors.
I have four special memories of the journal's early years, one light and three more serious:

The white feather - a sign of honor or surrender? Being a true-bred.New Englander, I never throw anything of any value away, so I kept

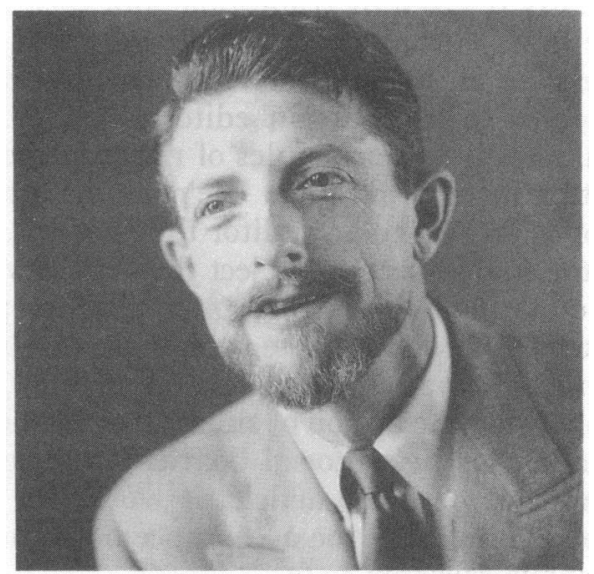

Ogden R. Lindsley, 1958. 
in a small cardboard box the wing and tail feathers from a pigeon that died. Ferster and Skinner had reported on the bird's behavior in Schedules of Reinforcement, so it was a pretty famous pigeon.

When I started acknowledging the receipt of checks paying for charter subscriptions to JEAB, I thought it a very nice touch to include a White Carneau feather from one of these famous Harvard pigeons that helped start it all. An heroic feather. A memento from the only really necessary part of the experimentthe subject.

All went as planned.

Except . . . upon receiving his feather, Charlie Ferster telephoned in anger. Usually very mild mannered and calmly tempered, Charlie was furious. "You should have talked to me before you did that!" he shrieked over the phone. "Don't you realize that the white feather is a symbol of surrender? This is a terrible omen-a terrible way to announce a new journal!"

I mumbled back that feathers, like everything else, are relative. That these are not just any old white feathers but White Carneau feathers. They are the feathers of pigeon nobility! These and many other such platitudes had no effect. Charlie still thought white feathers connoted surrender, not honor.

The conservatives always win. The second memory is rather heavy, and to me a little sad. Primarily because of our single-subject research designs, our data displayed in cumulative response recordings, our lack of traditional statistical measures, and our unusual descriptive language, our articles were frequently rejected by traditional journals. I saw our new journal as an opportunity, not only to create an avenue for research publication but also to innovate in editorial policy. We could apply the principles of reinforcement to editing for the first time. We could let authors submit articles to any editor they wished. The editor could accept or reject the article with a note stating why. If accepted, the accepting editor's acceptance note would be published immediately after the article. If rejected, that author had the option of submitting to another member of the editorial board. If the second editor accepted the article, it would be published along with the acceptance note and the previous rejection note.
If the published research was effective and its results were corroborated by others, then the behavior of the accepting editors would be positively reinforced along with that of the authors. If the research proved mundane or flawed, then the accepting editor would share in this discredit along with the author. If an editor accepted no articles over a period of time (say three years), he would be extinguished off the board. This would mean that no authors wanted him to edit their articles, and therefore he should not serve the journal. The natural consequences operating in this fashion would shape up a truly powerful journal.

Ferster, Keller, Lindsley, and Skinner were among the liberals who argued for a creative new editorial policy. Azrin, Brady, Herrnstein, and Sidman were among those arguing for a strong editorial policy following the lines of traditional APA journals.

When I came up for air after serving as Business Manager for the journal's first two years, I submitted to JEAB an article on the analysis of psychotic behavior. It was rejected with heavy requests for rewriting. Angered at being rejected by the journal I helped found, I submitted the article to Diseases of the Nervous System and it was accepted without rewrite. A reprint of this article won the Hofheimer Annual Research Prize of the American Psychiatric Association in 1962. Obviously, the conservatives won.

Analysis versus synthesis. When suggestions for the name of the new applied journal were circulated by Mont Wolf, I was against using "analysis" without its key adjective "experimental." The reason for the expensive laboratory walls, the reinforcement dispensers, and the white-noise masking sounds in my research with the psychotics was to control variables. Only laboratory controls could ensure that you were manipulating only one variable at a time. That was the essence of experimental in contrast to statistical analysis.

On the ward or in the classroom, you could not manipulate a single variable at a time. You could not present a token without also approaching the learner, usually grasping his or her hand, waiting for eye contact, then smiling as you closed the learner's hand around the token. You could not present the token to a learner without the other learners in the room also reacting. The token was merely a catalyst 
for a host of other variables with which it was confounded. Delivering imaginary tokens often worked as well.

In the applied work we could not do true, clean behavior analysis. Instead, what we did was behavior synthesis, building behavior by combining variables. For this reason I suggested the title Journal of Experimental Synthesis of Behavior. The laboratory research would be called analysis and be published in JEAB. The applied research would be called synthesis and published in JESB. But it was voted down; the distinction was probably too fine and the term too novel.

JABA editors rejected an article of mine for the first issue because the display of rate data in standard celeration charts was thought too difficult for readers. In anger, my graduate students submitted a standard celeration chart without description as an advertisement. There it is on the inside of the back cover of the first issue of JABA. But it is not a published article. Even among radicals, the conservatives always win.

When your reaction is primarily against something, it is very easy to take on the coloration of that which you oppose. Since most of us were reacting against the APA journals, soon our form was similar to theirs. The only surviving policy innovation is ownership of the journal by SEAB, which is made up of members and former members of its Board of Directors. All else is similar to traditional APA journal policy.

Standardization is hopeless only in America. The fourth memory is also sad to me, because it marks how difficult it is to generate timesaving skills, even among behavioral scientists.

In those founding discussions of editorial policy there was also interest in restricting data display to cumulative response records. The cumulative record was our most powerful tool, forcing us to look at rate of response and keep- ing us from getting caught up in relatively trivial changes in rate. It was easy to share large numbers of records at meetings since no time was wasted describing the coordinates of unique data charts. Since cumulative records were automatically generated by the animals and the apparatus, there was no possibility for observer bias. Also, automatic recording meant that you could be preserving the behavior of 15 pigeons or humans even while you were out of town at a professional meeting. High efficiency, indeed!

Not only did the idea of restricting publication of sample data to cumulative response records get voted down, but so did the idea that each article must display some of its rate data in cumulative response charts. Since the late fifties, JEAB has published a smaller and smaller proportion of cumulative records and a smaller and smaller proportion of rate of response data.

Four JEAB memories: one chuckle and three frustrations. We weren't ready for natural consequences for editing, the notion of experimental synthesis, or standardized charts in articles. They are still good ideas. Want to start a journal?

Would I collect dollars for JEAB again? You bet! It was wonderful to be part of that productive, exciting group of scientists. Would I help start another journal and collect dollars for it? You bet! I still have the little box of vintage White Carneau feathers and could use them to reinforce the checks from the charter subscribers. Isn't that a great idea?
Department of Educational Policy and Administration
School of Education-Carberry Hall
University of Kansas
Lawrence, Kansas 66045 